\title{
Root and Shoot Characteristics of Peach Trees with Different Growth Habits
}

\author{
Thomas Tworkoski and Ralph Scorza \\ U.S. Department of Agriculture, Agricultural Research Service, Appalachian Fruit Research Station, 45 \\ Wiltshire Road, Kearneysville, WV 25430
}

\begin{abstract}
AdDitional INDEX words. Prunus persica, root architecture, specific root length, topology, carbon partitioning
Abstract. Shoot and root characteristics of four peach tree [Prunus persica (L.) Batsch (Peach Group)] growth habits (compact, dwarf, pillar, and standard) were studied. In compact trees, leaf number $\left(1350 /\right.$ tree) was twice, but leaf area $\left(6 \mathrm{~cm}^{2} /\right.$ leaf) was half that of pillar and standard trees. The number of lateral branches in compact trees (34) was nearly three times more than in pillar and standard trees. Leaf area index (total one-side leaf area per tree divided by the canopy cross-sectional area of the tree) of pillar trees was greater than compact, dwarf, and standard trees (13 compared with 4, 4, and 3, respectively) due to a narrower crown diameter. Dwarf trees were distinct with few leaves (134/tree) and less than half the roots of the other growth habits. Compact trees produced more higher order lateral (HOL) roots than pillar and standard trees. More second order lateral (SOL) roots were produced by compact than standard trees $(1.2$ vs. 0.8 SOL roots per centimeter first order lateral root). Pillar trees had higher shoot : root dry weight (DW) ratios (2.4) than compact and standard trees (1.7 for both) due to lower root DWs. Root topology was similar among compact, pillar, and standard peach trees but root axes between branch junctions (links) were significantly longer in compact trees. Compact trees had more and longer HOL roots in roots originating near the root collar (stem-root junction) (i.e., more fibrous roots) and this appeared to correlate with more lateral branches in the canopy. These results indicate significant differences in root as well as shoot architecture among growth habits that can affect their use as scion or rootstock cultivars.
\end{abstract}

Peach trees [Prunus persica (Peach Group)] with diverse shoot growth habits have been identified for developing new cultivars with improved light penetration, reduced need for pruning, or high yield under high density cultivation (Scorza, 1984, 1988; Scorza et al. 1984, 1986). Pillar peach trees have narrow canopies with upright branches, and few lateral branches and appear to be amenable to high-density plantings (Scorza et al., 1989). Compact peach trees are $\approx 20 \%$ smaller than standard trees. While they produce dense canopies due to long second and third order branches they produce more spurs and react less to pruning than standard trees (Mehlenbacher and Scorza, 1986; Scorza, 1984, 1987, 1988; Scorza et al., 1989, 1986). Dwarf trees can be very small and thus planted at high densities for high yields per land area, but the short internodes produce dense canopies that are difficult to manage (Hansche and Beres, 1980; Scorza, 1984, 1988).

Shoot and canopy growth and architecture of pillar, dwarf, and compact trees have been described (Bassi et al., 1994; Scorza, 1984) but information on root systems of these growth types is limited. Glenn and Scorza (1992) studied reciprocal grafts of dwarf and standard scions on dwarf and standard seedling rootstocks for one growing season in a greenhouse. They found that the scion growth habit, not the rootstock growth habit, affected root length density, leaf, stem, and total above ground dry weight (DW). They reported that root systems supporting dwarf scions had elevated cytokinin and auxin activity and that these root systems exhibited a greater amount of fine roots than those supporting standard scions. Giovannini et al. (1994) studied dwarf, pillar, and standard trees grafted onto standard seedling rootstocks for one growing season in a greenhouse. They found that the scions had no effect on xylem area percentage of the root system, the number of vessels per square millimeter of root, cross sectional area of the largest xylem vessels,

Received for publication 6 Dec. 2000. Accepted for publication 7 Aug. 2001 Mention of trade names or proprietary products is for the convenience of the reader only, and does not constitute endorsement or preferential treatment by the USDA-ARS. The cost of publishing this paper was defrayed in part by the payment of page charges. Under postal regulations, this paper therefore must be hereby marked advertisement solely to indicate this fact. specific root length (total root length divided by root DW) of roots $<1 \mathrm{~mm}$ in diameter, or rooting angle of the primary roots. Fine and large root length densities were affected by the scion at the end of the growing season with densities decreasing from standard > pillar > dwarf trees. Dwarf tree root system DW had higher percentages of fine roots than standard or pillar trees. They found that the smaller canopies of the pillar and dwarf trees affected the seedling root systems by producing lower leaf to fine-root ratios than occurred with standard scions. Giovannini et al. (1994) and Glenn and Scorza (1992) indicate that in grafted peach trees, the scion can affect certain root characteristics but the root system appears to have little effect on the scion.

We have found no studies of the shoot/root systems on nongrafted peach trees of various growth habits. Such information is important to understand the natural interactions of root and shoots of different growth habits and as a base line from which to compare the effects of grafting on both root and shoot growth of these unique genotypes. In addition, knowledge of root system morphology and architecture and variation of root characteristics among peach genotypes may have practical implications for mineral nutrient and water management of peach trees planted at different densities. Characterizing shoot and root systems can be important in selection and development of rootstocks and own-rooted trees. Therefore, the objectives of this research were to determine and compare 1) root system and individual root morphology of four peach genotypes with different shoot morphologies and 2) the root and shoot branch morphology and DW distribution of each growth habit.

\section{Materials and Methods}

Plants. Parent crosses used for standard, compact, dwarf, and pillar genotypes were described previously (Scorza et al., 1986, 1989). Seeds were germinated in peat and five seedlings from each growth habit were planted in 128-L plastic trash barrels in June 1998 (Fig. 1). The soil used was a Hagerstown silt loam, a fine, mixed, mesic Typic Hapludalf, that was collected from the top layer $(20 \mathrm{~cm})$ of land that had not been farmed for 20 years. The soil was sieved 
to pass a $1 \mathrm{~cm}$ screen. Trees were grown under field conditions without fertilization. Pots were hand weeded and received supplemental water every 2 weeks. By the end of the 1998 growing season the roots had grown to the bottom but not the sides of the $128-\mathrm{L}$ barrels. This group of five trees was used to determine shoot and root system branching and weight distribution characteristics of the four growth habits.

A second group of three seedlings from each growth habit were transplanted into 20-L plastic pots with a commercial growing medium (ProMix-DX; sphagnum peat, $75 \%$ to $85 \%$ and perlite) and grown in the greenhouse for $5 \mathrm{months}\left(560 \mu \mathrm{mol} \cdot \mathrm{m}^{-2} \cdot \mathrm{s}^{-1}\right.$ photosynthetically active radiation, $23 \pm{ }^{\circ} \mathrm{C}$ air temperature). No supplemental lighting or fertilization was used but trees were watered daily. By the end of the 1998 growing season, the roots had grown to the sides and bottom of the 20 -L pots. These plants were used to measure root configuration (topology and geometry) based on root link composition (Fitter, 1985).

BRANCHING AND DRY WEIGHT DISTRIBUTION. Stems and roots were
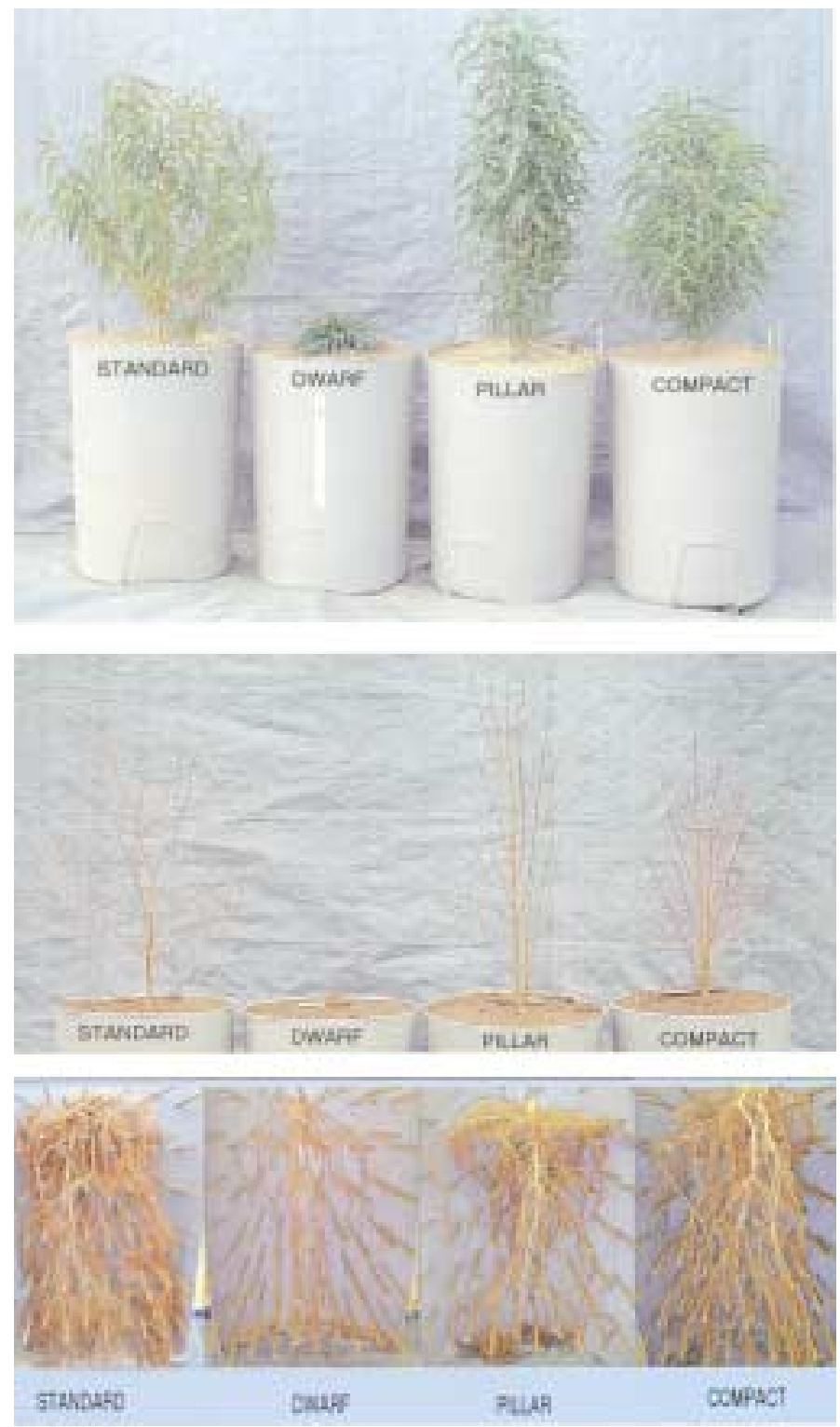

Fig. 1. Standard, dwarf, pillar, and compact (left to right) peach tree growth habits. Shoots with leaves (top), shoots with no leaves (middle), and excavated roots (bottom). harvested from trees grown in the 128-L barrels in Oct. 1998 (Fig. 1). All leaves were removed, counted, and total leaf area measured for each plant with a portable area meter (LI-3000; LI-COR, Inc., Lincoln, Neb.). Shoots were then cut from roots at the root collar (stem-root junction) and tree height and number of stem internodes along the main axis were measured. Additional measurements were average crown diameter from two perpendicular measurements at the widest part of the crown and crown height from the bottom to top of the crown. Leaf area index (LAI) was calculated as the total oneside leaf area per tree divided by the canopy cross-sectional area of the tree. Leaf area ratio (LAR) was calculated as the total one-sided leaf area per tree divided by the tree DW. DWs were measured after drying plant parts for $3 \mathrm{~d}$ at $70{ }^{\circ} \mathrm{C}$.

Branch angle from the vertical for each tree was based on the average of three branches growing from the main axis per tree. Shoot branches were measured as the total number, length, and DW of first order lateral (FOL) stems off the main stem axis. Number, length, and DWs of second order lateral (SOL) stems and higher order lateral (HOL) stems were also measured.

After harvesting the above-ground portion of a tree, the root system was harvested. Half of each pot was removed, exposing the soil monolith, and a needle board was inserted to stabilize the root system while soil was gently washed away (Fig. 1). The main root axis length was measured and the frequency of FOL roots was recorded as the total number of FOL roots divided by main root axis length. Three FOL roots and the associated subsystem of roots were cut from within $10 \mathrm{~cm}$ of the root collar and another three FOL roots were cut from 10 to $20 \mathrm{~cm}$ of the root collar from each tree. Within each of the six root subsystems the following measurements were taken to characterize root branching: length of FOL root, number and length of SOL roots per FOL root, and total length of HOL roots per FOL root. The Computer Image Analysis System (CID, Inc., Vancouver, Wash.) was used to measure root length. Specific root length (SRL) was calculated as total root length divided by root DW. DWs of lateral roots $<1$ and $>1 \mathrm{~mm}$ diameter from within $10 \mathrm{~cm}$ or farther than $10 \mathrm{~cm}$ from the root collar were measured for each root system.

The experimental design was completely randomized with four growth habit treatments and five single-tree replications. Multiple samples per tree (e.g., three FOL roots within $10 \mathrm{~cm}$ of the root collar) were analyzed as subsamples and each tree was an experimental unit. Shoot and root variables were compared among growth forms with analysis of variance (ANOVA) and mean separation

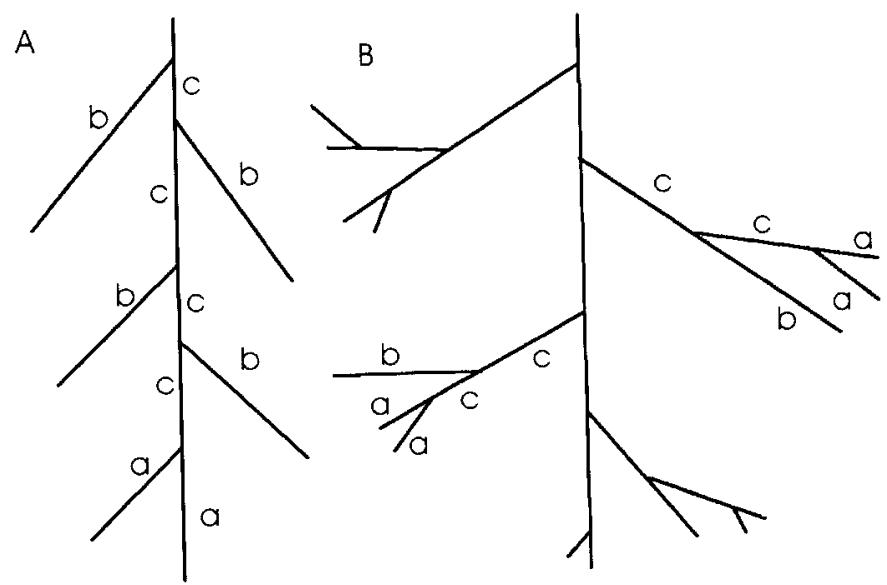

Fig. 2. Diagrammatical representation of $(\mathbf{A})$ herringbone and $(\mathbf{B})$ dichotomous root systems and root links measured (after Fitter and Stickland, 1991): exterior-exterior (a), exterior-interior (b), and interior-interior (c). 
based on Ryan-Einot-Gabriel-Welsch test (SAS, 1988).

Root CONFiguration. Trees planted in the 20-L containers and grown in the greenhouse were harvested at the end of the growing season and two SOL roots (and associated HOL roots) from each root system were sampled to characterize root configuration (topography and geometry) as described by Fitter (1985). These root subsystems were removed from a FOL root close to the root collar (within five links of the root collar). The topology of each root subsystem was determined based on connection patterns of root links (Fitter, 1985).

Root links are root axes or pathways that join at branch junctions and are analogous to internodes of a shoot (Fig. 2). The distal end of each link can be a root tip or a branch junction while the basal end will always be a branch junction to other links. An exterior-exterior link has a root tip and a basal junction to the basal end of a second link with a root tip and to the distal end of a third link. An exterior-interior link has a root tip and a basal junction to only the distal end of another link. Interior-interior links do not have root tips. The number and length of links were measured for each root link type for each root subsystem with the computer imaging system (CID, Inc.).

The topology of a subsystem of each root system was measured according to the number of root links. Number of links in pathways (configuration topology) were calculated for total links in all paths from root tip to the root collar (Pe), total number of exterior links or root tips on a SOL root subsystem (magnitude or $\mu$ ), and total number of links in the longest path from a root tip to the root collar. The relationship of Pe to $\mu$ reflects the topology of the root system. A low Pe to $\mu$ ratio indicates a dichotomous root system that may be effective to exploit a restricted soil volume (Fitter, 1985). A high Pe to $\mu$ ratio indicates a more herringbone topology that explores new soil. The experiment was a completely randomized design with a root subsystem being the experimental unit and six replications. The Pe to $\mu$ relationship was characterized by regression and slopes were compared among growth forms with ANOVA (SAS, 1988).

\section{Results and Discussion}

Sноот. Large differences between growth habits occurred in leaf, crown, and branch characteristics. Compact trees had about twice the leaf number but half the area per leaf of pillar and standard trees, resulting in the same total leaf area per tree (Table 1). Compact trees also had nearly three times more SOL stems than pillar and standard trees (Table 2). Height, number of FOL stems, and branch angle were similar between compact and standard trees. The dense appearance of compact tree crowns (Fig. 1) was due to numerous SOL stems and leaves and these traits indicate that compact trees had more growing meristems in the shoot than the other growth habits.

Pillar trees had the same total leaf area but a narrower crown diameter than compact and standard trees (Table 1). As a result, the LAI of pillar trees (13.4) was about four times greater than compact and standard trees. LAI values up to 8 are common for many mature crop and deciduous forest communities (Salisbury and Ross, 1978). With high LAI, leaves low in the canopy are extensively shaded, receiving $<1 \%$ of full sunlight, and these leaves can reduce productivity due to respiration. In pillar trees, the large area per leaf may be an adaptive response to self shading (Table 1). Leaf area enlargement is an adaptive response of many trees to shading (Fitter and Hay, 1987). Large LAI may be more a factor in determining the planting densities of pillar than standard trees because intense shading may adversely affect yield of neighboring trees. In a previous report, pillar peach trees with narrow canopies fruited poorly (Bassi et al. 1994). It is possible that shading may have affected flower bud formation. Yet, Bassi et al. (1994) also found that in pillar trees, fruit-producing shoots were well-distributed between the upper and lower portions of the canopy. Conversely, Baraldi et al. (1994) demonstrated that flower bud differentiation was less in the lower layer of a standard peach canopy. In their work LAI was greater in the lower (up to 13) than in the upper (6) canopy and that altered both irradiance and light quality.

Pillar tree crowns had similar number of growing meristems in the shoot as standard trees based on number of leaves, FOL stems,

Table 1. Leaf and crown characteristics of compact, dwarf, pillar, and standard growth habits of peach trees.

\begin{tabular}{|c|c|c|c|c|c|c|}
\hline $\begin{array}{l}\text { Growth } \\
\text { habit }\end{array}$ & $\begin{array}{c}\text { Leaves/tree } \\
\text { (no.) }\end{array}$ & $\begin{array}{c}\text { Total leaf } \\
\text { area/tree } \\
\left(\mathrm{cm}^{2}\right)\end{array}$ & $\begin{array}{l}\text { Area/leaf } \\
\left(\mathrm{cm}^{2}\right)\end{array}$ & $\mathrm{LAI}^{\mathrm{z}}$ & $\begin{array}{l}\text { Crown } \\
\text { diam } \\
(\mathrm{cm})\end{array}$ & $\begin{array}{c}\mathrm{LAR}^{\mathrm{Z}} \\
\left(\mathrm{cm}^{2} \cdot \mathrm{g}^{-1}\right. \\
\text { whole plant })\end{array}$ \\
\hline Compact & $1350 \mathrm{a}^{\mathrm{y}}$ & $8335 \mathrm{a}$ & $6.1 \mathrm{c}$ & $3.8 \mathrm{~b}$ & $54 \mathrm{a}$ & $34 \mathrm{~b}$ \\
\hline Dwarf & $134 \mathrm{c}$ & $2100 \mathrm{~b}$ & $16.5 \mathrm{a}$ & $4.3 \mathrm{~b}$ & $25 \mathrm{~b}$ & $73 \mathrm{a}$ \\
\hline Pillar & $671 \mathrm{~b}$ & 9472 a & $14.0 \mathrm{a}$ & $13.4 \mathrm{a}$ & $31 \mathrm{~b}$ & $42 \mathrm{~b}$ \\
\hline Standard & $783 \mathrm{~b}$ & 8220 a & $10.5 \mathrm{~b}$ & $3.1 \mathrm{~b}$ & $59 a$ & $34 \mathrm{~b}$ \\
\hline
\end{tabular}

${ }^{\mathrm{Z}} \mathrm{LAI}=$ leaf area index, LAR $=$ leaf area ratio.

${ }^{\mathrm{y}}$ Mean separation within columns, by Ryan-Einot-Gabriel-Welsch multiple F test $(P \leq 0.05)$. Each mean was based on five trees.

Table 2. Shoot characteristics of compact, dwarf, pillar, and standard growth habits of peach trees.

\begin{tabular}{|c|c|c|c|c|c|c|}
\hline $\begin{array}{l}\text { Growth } \\
\text { habit }\end{array}$ & $\begin{array}{l}\mathrm{Ht} \\
(\mathrm{cm})\end{array}$ & $\begin{array}{c}\text { Nodes on } \\
\text { main axis } \\
\quad(\text { no. })\end{array}$ & $\begin{array}{c}\text { FOL } \\
\text { stems } \\
\text { on tree }^{\mathrm{z}} \\
\text { (no.) }\end{array}$ & $\begin{array}{c}\text { SOL } \\
\text { stems } \\
\text { on tree } \\
\text { (no.) }\end{array}$ & $\begin{array}{c}\text { Avg } \\
\text { branch } \\
\text { angle } \\
\left(^{\circ}\right)\end{array}$ & $\begin{array}{c}\text { Frequency } \\
\text { of FOL } \\
\text { stems on } \\
\text { main axis } \\
\text { (no./cm) }\end{array}$ \\
\hline Compact & $69 b^{y}$ & $56 \mathrm{a}$ & $25 \mathrm{a}$ & $34 \mathrm{a}$ & $52 \mathrm{a}$ & $0.4 \mathrm{~b}$ \\
\hline Dwarf & $7 \mathrm{c}$ & $54 \mathrm{a}$ & $5 \mathrm{c}$ & $1 \mathrm{c}$ & $44 \mathrm{~b}$ & $0.6 \mathrm{a}$ \\
\hline Pillar & $89 a$ & $60 \mathrm{a}$ & $20 \mathrm{~b}$ & $11 \mathrm{~b}$ & $40 \mathrm{~b}$ & $0.3 \mathrm{~b}$ \\
\hline Standard & $76 \mathrm{~b}$ & $56 \mathrm{a}$ & $23 \mathrm{ab}$ & $14 \mathrm{~b}$ & $58 \mathrm{a}$ & $0.3 \mathrm{~b}$ \\
\hline
\end{tabular}

${ }^{\mathrm{z} F O L}=$ first-order lateral and $\mathrm{SOL}=$ second-order lateral.

y Mean separation within columns by Ryan-Einot-Gabriel-Welsch multiple F test $(P \leq 0.05)$. Each mean was based on five trees. 
Table 3. Lateral root characteristics of compact, dwarf, pillar, and standard growth habits of peach trees.

\begin{tabular}{|c|c|c|c|c|c|c|c|}
\hline $\begin{array}{l}\text { Growth } \\
\text { habit }\end{array}$ & $\begin{array}{l}\text { Distance } \\
\text { of FOL } \\
\text { root from } \\
\text { the root } \\
\text { collar } \\
(\mathrm{cm})\end{array}$ & $\begin{array}{l}\text { Total length } \\
\text { of all roots } \\
\text { growing } \\
\text { from one } \\
\text { FOL root } \\
\text { (cm) }\end{array}$ & $\begin{array}{l}\text { Length of } \\
\text { FOL root } \\
\quad(\mathrm{cm})\end{array}$ & $\begin{array}{l}\text { Length } \\
\text { of all } \\
\text { SOL roots } \\
\text { on one } \\
\text { FOL root } \\
\text { (cm) }\end{array}$ & $\begin{array}{l}\text { Length } \\
\text { of all } \\
\text { HOL roots } \\
\text { on one } \\
\text { FOL root } \\
\text { (cm) }\end{array}$ & $\begin{array}{l}\text { Frequency } \\
\text { of SOL } \\
\text { roots } \\
\text { on one } \\
\text { FOL root } \\
\text { (no./cm) }\end{array}$ & $\begin{array}{c}\text { Total } \\
\mathrm{SRL}^{\mathrm{z}} \\
\left(\mathrm{cm} \cdot \mathrm{g}^{-1}\right)\end{array}$ \\
\hline Compact & $0-10$ & $4316 a^{y}$ & $62 a$ & $690 a$ & $3564 a$ & $1.2 \mathrm{a}$ & $893 \mathrm{~b}$ \\
\hline Dwarf & & $811 \mathrm{c}$ & $70 a$ & $294 \mathrm{~b}$ & $448 \mathrm{c}$ & $0.4 \mathrm{c}$ & $1555 \mathrm{a}$ \\
\hline Pillar & & $2575 \mathrm{~b}$ & $59 a$ & $537 \mathrm{a}$ & 1979 b & $0.8 \mathrm{~b}$ & $1047 \mathrm{~b}$ \\
\hline Standard & & $2909 \mathrm{~b}$ & $51 \mathrm{a}$ & $492 a b$ & $2367 \mathrm{~b}$ & $0.8 \mathrm{~b}$ & $1139 \mathrm{~b}$ \\
\hline Compact & $10-20$ & $2033 \mathrm{a}$ & $71 \mathrm{a}$ & $667 \mathrm{~b}$ & $1296 \mathrm{a}$ & $1.0 \mathrm{a}$ & $898 \mathrm{~b}$ \\
\hline Dwarf & & $822 b$ & $71 \mathrm{a}$ & $364 c$ & $387 \mathrm{~b}$ & $0.4 \mathrm{c}$ & $1301 \mathrm{a}$ \\
\hline Pillar & & $2242 \mathrm{a}$ & $76 a$ & $946 a$ & $1220 \mathrm{a}$ & $0.9 \mathrm{a}$ & $877 \mathrm{~b}$ \\
\hline Standard & & $2159 \mathrm{a}$ & $74 \mathrm{a}$ & $712 a b$ & $1372 \mathrm{a}$ & $0.7 \mathrm{~b}$ & $649 \mathrm{~b}$ \\
\hline
\end{tabular}

${ }^{\mathrm{z}} \mathrm{FOL}=$ first order lateral, $\mathrm{SOL}=$ second order lateral, $\mathrm{HOL}=$ higher order lateral, and SRL $=$ specific root length.

${ }^{y}$ Within each column and distance of FOL root from the root collar, means separation by Ryan-Einot-Gabriel-Welsch multiple F test $(P \leq 0.05)$. Each mean was derived from five trees.

and SOL stems (Tables 1 and 2). The major distinction of pillar trees was that they had narrower branch angles and were more upright than compact and standard trees (Table 2, Fig. 1).

Dwarf trees had the fewest leaves and least leaf area per tree (Table 1). Although dwarf trees were one-tenth the height of the other growth habits they had the same number of internodes along the main shoot axis, suggesting that this trait is genetically conserved among peach growth habits (Table 2). Dwarf trees had the fewest number of FOL and SOL stems, indicating the least shoot branching and fewest growing meristems in the shoot of all the growth habits. Since dwarf tree LAR was high, a smaller proportion of photosynthate would be needed for nonphotosynthesizing stems and roots than in standard trees. It is possible that dwarf trees could be efficient cropping plants if light penetration in the canopy was increased.

RoOT BRANCHING. As with shoots, root characteristics differed among the growth habits. Roots growing from within $10 \mathrm{~cm}$ of the root collar had at least 50\% more total root length per FOL root in compact trees as pillar and standard trees (Table 3). Most of this length was associated with HOL roots. In addition, compact trees had a greater frequency of SOL roots per FOL root than the other growth habits. Compact trees also had the greatest number of SOL stems (Table 2). One could speculate that the processes which regulate development of a root system may exert a coordinated morphological effect on the shoot, branching in this case. For example, cytokinin and auxin ratios may affect both shoot budbreak and development of lateral roots (Bellini et al., 1997; Woolley and Wareing, 1972). It is noteworthy that practically no differences were found among compact, pillar, and standard trees when roots from 10 to $20 \mathrm{~cm}$ below the root collar were analyzed. This may argue that shoot effects diminish with increased distance from the root collar.

Pillar and standard tree root systems were largely similar (Table 3). Stems of pillar shoots had a narrower angle from the vertical than standard stems but no similar variable was measured in the root system.

The dwarf tree root system was distinct with least total, SOL, and HOL root length per FOL root (Table 3). Dwarf also had the least frequency of SOL per FOL root. As with dwarf tree shoots, dwarf root systems had the least branching and fewest growing meristems in the root of all the growth habits (Table 3). With its small root system, dwarf trees had the greatest SRL, indicating that the roots were responding to soil conditions or may have been developmentally juvenile (Fitter, 1985). Some root confinement of compact, pillar, and standard trees may have decreased the SRL in these growth habits (Table 3).

RoOT CONFIGURATION. Individual SOL and the associated HOL roots (root subsystem) of compact trees had greater length of root links but the same number of exterior links $(\mu)$ and total links in all paths $(\mathrm{Pe})$ as root subsystems of standard trees (Table 4). The compact tree root system in shallow soil appears to be one with high frequency of SOL roots from each FOL root and large link length of the root subsystem associated with each SOL root (Tables 3 and 4).

Table 4. Root configuration of second-order and higher-order lateral roots (links) growing from one first-order lateral root of compact, dwarf, pillar, and standard growth habits of peach trees.

\begin{tabular}{|c|c|c|c|c|c|c|}
\hline $\begin{array}{l}\text { Growth } \\
\text { habit }\end{array}$ & $\begin{array}{c}\mu^{z} \\
\text { (no.) }\end{array}$ & $\begin{array}{c}\text { Links in } \\
\text { longest } \\
\text { path } \\
\text { (no.) }\end{array}$ & $\begin{array}{l}\mathrm{Pe}^{\mathrm{y}} \\
\text { (no.) }\end{array}$ & $\begin{array}{l}\text { Length } \\
\text { of all } \\
\text { interior- } \\
\text { interior } \\
\text { links } \\
(\mathrm{cm})\end{array}$ & $\begin{array}{l}\text { Length } \\
\text { of all } \\
\text { exterior- } \\
\text { interior } \\
\text { links } \\
(\mathrm{cm})\end{array}$ & $\begin{array}{l}\text { Length } \\
\text { of all } \\
\text { exterior- } \\
\text { exterior } \\
\text { links } \\
\text { (cm) }\end{array}$ \\
\hline Compact & $60 a^{x}$ & $23 \mathrm{a}$ & $850 \mathrm{a}$ & $168 \mathrm{a}$ & $111 \mathrm{a}$ & $92 \mathrm{a}$ \\
\hline Dwarf & $17 \mathrm{c}$ & $10 \mathrm{~b}$ & $123 \mathrm{c}$ & $10 \mathrm{~b}$ & $6 \mathrm{~b}$ & $6 \mathrm{~b}$ \\
\hline Pillar & $40 \mathrm{~b}$ & $22 \mathrm{a}$ & $496 \mathrm{~b}$ & $65 \mathrm{~b}$ & $51 \mathrm{ab}$ & $49 \mathrm{ab}$ \\
\hline Standard & $68 \mathrm{a}$ & $22 \mathrm{a}$ & $883 \mathrm{a}$ & $47 \mathrm{~b}$ & $33 \mathrm{~b}$ & $34 \mathrm{~b}$ \\
\hline
\end{tabular}

${ }^{\mathrm{z}} \mu$ represents the number of exterior links or root tips.

yPe represents the total links in all paths from root tip to root collar.

${ }^{x}$ Mean separation within columns by Ryan-Einot-Gabriel-Welsch multiple $\mathrm{F}$ test $(P \leq 0.05)$. Each mean was derived from six roots from three trees. 


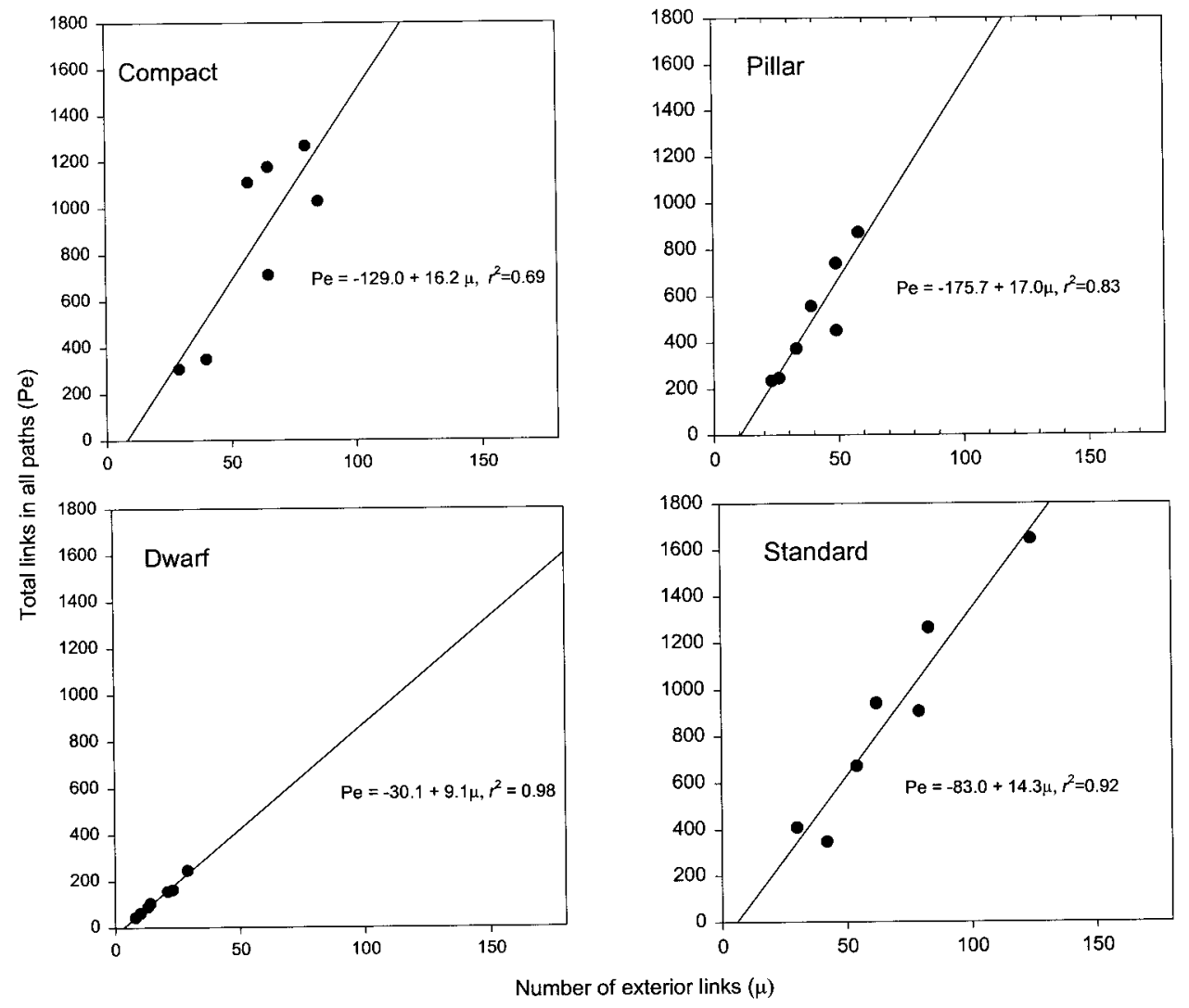

similar among compact, pillar, and standard trees but root DW of pillar trees was significantly lower (Table 5). Reduced root DW of pillar when compared with standard and compact trees may have resulted from self-shading of the shoot due to the high LAI (Table 1). With shade there may be less net carbon gain and plants often divert carbon to shoot growth at the expense of root growth in response to shading (Boote, 1977). It is possible that the greater shoot to root DW ratio of pillar trees would occur with pillar trees grafted onto standard seedling rootstocks. Giovannini et al. (1994) found reduced root system DW when pillar trees were budded onto standard rootstock. Reduced root mass could require careful fertilization and irrigation to meet the mineral nutrient requirements of peach trees and avoid loss of yield.

Dry matter distribution among organs was similar among compact, pillar, and standard trees (Fig. 4). Dwarf trees had different weight distributions. A higher percentage weight was distributed to leaves and less to FOL stems in dwarf than the other growth habits.

Fig. 3. Relationship of total links in all paths (Pe) and number of exterior links $(\mu)$ in secondary and higher order lateral root subsystems of compact, dwarf, pillar, and standard peach tree growth habits.

Plants with a large Pe to $\mu$ ratio have a herringbone configuration (Fitter and Stickland, 1991) and greater increases in Pe with increasing $\mu$ suggest a root system that may be exploring new soil regions rather than exploiting a restricted volume of soil. Compact trees seem to have greater root branch frequency and more root length than other growth habits (Table 4). However, the root subsystems of SOL and HOL roots of compact, pillar, and standard trees have similar configurations when Pe was viewed against $\mu$ (i.e., they have the same slopes in a plot and based on ANOVA; Fig. 3). Taken together, the branching and topological data suggest that quantitative differences in root length and root frequency occur but the root subsystem configuration (e.g., herringbone pattern vs. dichotomous branching) are similar among compact, pillar, and standard peach trees.

Dwarf tree root subsystems had the smallest $\mu$ and Pe, reflecting few links in the small root system (Table 4). Length of links were short in dwarf trees which coincided with the short internode lengths of the main stem (Table 2). In the stem, the number of internodes of the main stem axis was the same among all growth habits but, in the root, link number was least in dwarf. Evidently, main stem internode number was under conservative genetic control but root link number was not similarly controlled among the four peach growth habits. The slope of Pe to $\mu$ was smaller in dwarf than in other growth habit trees reflecting a root system with a more dichotomous growth habit that will effectively exploit a restricted soil volume. This developmental pattern would be fundamentally different from the compact, pillar, and standard root subsystems, but because the dwarf root system was small with a high SRL (Table 3) the difference may not persist as the dwarf root system continues to enlarge.

Weight Distribution. Total tree DW and shoot DWs were
However, DW distribution among root system components was similar among all growth habits. One significant difference in weight distribution among root components was with the percentage plant $\mathrm{DW}$ in roots $<1 \mathrm{~mm}$ diameter from FOL originating within $10 \mathrm{~cm}$ of the root collar, which was greater in compact than dwarf or pillar trees (Fig. 4). The greater weight in small roots corroborates previously discussed data that compact trees had more lateral root growth (Table 3).

DW allocation patterns correlated with root morphology. Pearson correlation coefficients of root weight with root length and SRL were $0.93(P<0.01)$ and $-0.44(P<0.01)$, respectively. Roots from compact trees originating within $10 \mathrm{~cm}$ of the root collar weighed the most, were longest, and had the lowest SRL (Table 3, Fig. 4). In contrast, roots from dwarf trees weighed least but had the greatest SRL (Tables 3 and 5). In dwarf trees, the dry matter partitioned to the root was used to elongate main axes, not thicken or increase number of FOL and SOL roots (Table 3). Juvenile root systems and young roots will have high SRL (Fitter, 1985). It is possible that the root morphology of the dwarf growth habit may reflect a slowdeveloping root system.

Table 5. DWs of compact, dwarf, pillar, and standard growth habits of peach trees.

\begin{tabular}{lcccc}
\hline \hline Growth & $\begin{array}{c}\text { Whole } \\
\text { plant } \\
\text { habit }\end{array}$ & $\begin{array}{c}\text { Shoot } \\
(\mathrm{g})\end{array}$ & $\begin{array}{c}\text { Root } \\
(\mathrm{g})\end{array}$ & $\begin{array}{c}\text { Shoot : root } \\
\text { ratio }\end{array}$ \\
\hline Compact & $246 \mathrm{a}^{\mathrm{z}}$ & $156 \mathrm{a}$ & $90 \mathrm{a}$ & $1.7 \mathrm{~b}$ \\
Dwarf & $36 \mathrm{~b}$ & $23 \mathrm{~b}$ & $12 \mathrm{c}$ & $1.8 \mathrm{~b}$ \\
Pillar & $226 \mathrm{a}$ & $159 \mathrm{a}$ & $67 \mathrm{~b}$ & $2.4 \mathrm{a}$ \\
Standard & $243 \mathrm{a}$ & $150 \mathrm{a}$ & $92 \mathrm{a}$ & $1.7 \mathrm{~b}$
\end{tabular}

$\overline{{ }^{\mathrm{z}} \text { Mean separation within columns by Ryan-Einot-Gabriel-Welsch mul- }}$ tiple $\mathrm{F}$ test $(P \leq 0.05)$. Each mean was based on five trees. 


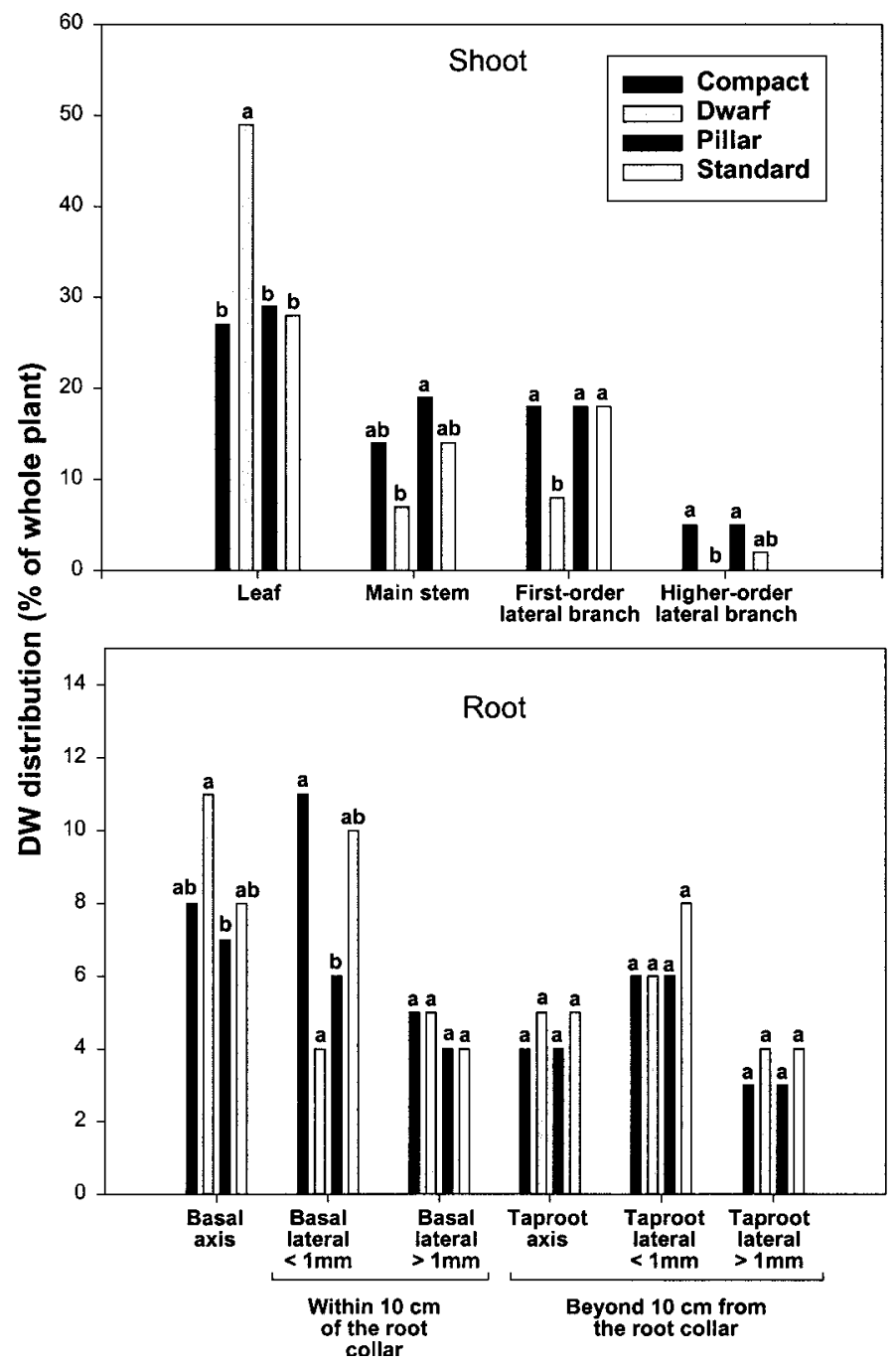

Fig. 4. DW distribution among shoot and root components of compact, dwarf, pillar, and standard peach tree growth habits. Within each plant part of the shoot and root, mean separation by Ryan-Einot-Gabriel-Welsch multiple F test $(P \leq$ $0.05)$ with arc sine transformation of the percentage data.

This research demonstrated differences in root system branching, configuration, and DW distribution among growth habits of peach trees that reflected distinctly different shoot architectures. For example, trees with dwarf shoots had the smallest root system and compact trees had high branch frequency in both shoots and roots. Knowledge of such coordinated shoot and root growth may lead to a fuller understanding of root-shoot interactions that are particularly important for cultural management and rootstock selection of fruit trees. Shoot- and root-produced hormones can regulate growth and hormonal differences among peach growth habits, which may explain branch frequency and elongation of stem internodes and root links. Despite these branching and length differences, topology of subsystems of second- and higher-order lateral roots were very similar for compact, pillar, and standard trees. That is, the total number of links in paths from exterior links (i.e., root tips) to the root collar were the same but the link lengths and number of subsystems differed. Thus, root branching frequency and root link lengths varied and may be selected in a peach breeding program but root system topology varied little and may not be subject to selection. Root system development and configuration affects plant exploration and exploitation of the soil and the niche occupied by plants in an ecosystem. The root traits characterized in this research may ultimately affect orchard soil and tree management decisions. Trees with DW distributed to a highly branched root system composed of longer root links may more readily absorb mineral nutrients from soil than a less-branched root system. Trees with smaller root systems, e.g., Pillar, may be more sensitive to limitations of soil resources. The consistency of the observed traits in a heterogeneous field soil and in response to genetic-environmental interactions must be evaluated to determine the significance of these root differences to growers and breeders.

\section{Literature Cited}

Baraldi, R., F. Rossi, O. Facini, F. Fasolo, A. Rotondi, M. Magli, and F. Nerozzi. 1994. Light environment, growth and morphogenesis in a peach tree canopy. Physiol. Plant. 91:339-345.

Bassi, D., A. Dima, and R. Scorza. 1994. Tree structure and pruning response of six peach growth forms. J. Amer. Soc. Hort. Sci. 119:378-382.

Bellini, C., M. Delarue, P. Vittorioso, J. Faure, E. Prinsen, H. Van Onckelen, I. Barlier, and M. Caboche. 1997. Phytohormones and development of lateral roots in Arabidopsis thaliana, p. 350-352. In: H.E. Flores, J.P. Lynch, and D. Eissenstat (eds.). Radical biology: Advances and perspectives on the function of plant roots. Amer. Soc. Plant Physiol., Rockville, Md.

Boote, K.J. 1977. Root : shoot relationships. Proc. Soil Crop Sci. Soc. Fla. 36:15-23.

Fitter, A.H. 1985. Functional significance of root morphology and root system architecture, p. 87-106. In: A.H. Fitter, D. Atkinson, D.J. Read, and M.B. Usher (eds.). Ecological interactions in soil: Plants, microbes and animals. British Ecol. Soc. Spec. Publ. 4. Blackwell Sci. Publ., Oxford, U.K.

Fitter, A.H. and R.K.M. Hay. 1987. Environmental physiology of plants. Academic Press, San Diego.

Fitter, A.H. and T.R. Stickland. 1991. Architectural analysis of plant root systems: 2. Influence of nutrient supply on architecture in contrasting plant species. New Phytol. 118:383-389.

Giovannini, D., D.M. Glenn, R. Scorza, and W.V. Welker. 1994. Dry matter distribution of three peach growth types. HortScience 29:1481-1483.

Glenn, D.M. and R. Scorza. 1992. Reciprocal grafts of standard and dwarf peach alter dry-matter partitioning and root physiology. HortScience 27:241-243.

Hansche, P.E. and W. Beres. 1980. Genetic remodeling of fruit and nut trees to facilitate cultivar improvement. HortScience 15:710-715.

Mehlenbacher, S.A. and R. Scorza. 1986. Inheritance of growth habit in progenies of 'Com-Pact Redhaven' peach. HortScience 21:124-126.

Salisbury, F.B. and C.W. Ross. 1978. Plant physiology. Wadsworth Publ. Co., Belmont, Calif.

Statistical Analysis Systems Institute, Inc. 1988. SAS/STAT user's guide. version 6. SAS, Cary, N.C.

Scorza, R. 1984. Characterization of four distinct peach tree growth types. J. Amer. Soc. Hort. Sci. 109:455-457.

Scorza, R. 1987. Identification and analysis of spur growth in peach [Prunus persica (L.) Batsch]. J. Hort. Sci. 62:449-455.

Scorza, R. 1988. Progress in the development of new peach tree growth habits. Compact Fruit Tree 21:92-98.

Scorza, R., G.W. Lightner, L.E. Gilreath, and S.J. Wolf. 1984. Reducedstature peach tree growth types: Pruning and light penetration. Acta Hort. 146:159-164.

Scorza, R., G.W. Lightner, and A. Liverani. 1989. The pillar peach tree and growth habit analysis of compact $x$ pillar progeny. J. Amer. Soc. Hort. Sci. 114:991-995.

Scorza, R., Li Zailong, G.W. Lightner, and L.E. Gilreath. 1986. Dry matter distribution and responses to pruning within a population of standard, semi-dwarf, compact, and dwarf peach, [Prunus persica (L.) Batsch] seedlings. J. Amer. Hort. Sci. 111:541-545.

Woolley, D.J. and P.F. Wareing. 1972. The interaction between growth promoters in apical dominance. I. Hormonal interaction, movement and metabolism of a cytokinin in rootless cuttings. New Phytol. 71:781-793. 